\title{
Epidemiological evaluation of genu valgum and flat feet in the child: experience of the martagão gesteira children's hospital
} \author{
Cortizo Garcia ${ }^{4}$ and Matheus Vasconcelos Goes Mendes ${ }^{3}$ \\ ${ }^{1}$ Residency Preceptor in the Orthopedic Department of the Martagão Gesteira Children's Hospital. Salvador, Brazil \\ ${ }^{2}$ Attendant Doctor at the Orthopedic Department of Martagão Gesteira Children's Hospital. Salvador, Brazil \\ ${ }^{3}$ Medicine Student at the Faculdade de Tecnologia e Ciências - FTC. Salvador, Bahia, Brazil \\ ${ }^{4}$ Medicine Student at the Universidad de Ciencias Empresariales y Sociales- UCES. Buenos Aires, Argentina
}

Fernando Cal Garcia Filho' ${ }^{*}$, Breno Leite Luz ${ }^{2}$, Mateus de Oliveira Trindade², Lucas Cortizo Garcia², Magda Leão Pinheiro ${ }^{3}$, Fernanda

\begin{abstract}
Introduction: It is known that angular deformities of the lower limbs are one of the biggest complaints in the children treated in our outpatient clinics, most of the time associated with deformities of the feet (flat feet). There is still no study in the specific literature regarding the correlation of both, although this association is frequently seen in practice.

Objective: To demonstrate the association between Genu Valgum and Flat Feet in children treated at the Orthopedics Clinic of the Martagão Gesteira Children's Hospital, based on gender, age ranges and weight ranges. Methodology: A descriptive and inferential study was carried out with 44 children of both sexes, aged between 2 and 14 years, with intermaleolar distance equal to or greater than $6 \mathrm{~cm}$, patients of spontaneous demand from the pediatric orthopedic clinic of the Martagão Gesteira Children's Hospital. The study lasted for 05 months and lasted from January 2013 to May 2013. Data analysis was performed through descriptive statistics. The Student's t-test was used, as well as the Kruskal-Wallis test for the independent variables, and the confidence interval (CI) of 95\% (p <0.05) for the significance of the study was estimated as an estimate accuracy.

Results: The mean age of the population was 03 years. Of the 44 patients studied, $70.50 \%$ were male. The average weight was $17.70 \mathrm{~kg}$. The minimum height recorded was $84.00 \mathrm{~cm}$, varying up to a maximum of $153.00 \mathrm{~cm}$. Another data evaluated was the intermaleolar distance (IMD), which had a minimum value of 6.50 $\mathrm{cm}$ and a maximum of $16.00 \mathrm{~cm}$. When IMD related to genders, male and female, there was no significance among them ( $\mathrm{p}=0.70)$. In order to correlate IMD with the age ranges, no association of significance was found between both $(\mathrm{p}=0.74)$. Checking the association between weight bands and IMD, no statistical significance was verified $(\mathrm{p}=0.40)$. Regarding the evaluation of the feet, $44(100 \%)$ patients presented flexible flat feet, all with bilateral alterations.
\end{abstract}

Conclusion: The present study demonstrated an association between valgus and flat feet.

\section{Introduction}

Angular deformities of the lower limbs in the child are changes that represent a normal and physiological stage of the development of the lower limbs most of the time. However, in some situations, they reflect the expression of some pathology, so the examiner must be able to distinguish between physiological changes and pathological changes. Physiological conditions tend to be corrected spontaneously and are commonly only observed, whereas pathological conditions should be investigated and treated Volpon JB [1].

Bertol P [2] reports that in the newborn, the normal alignment of the knee is around 10 to $15^{\circ}$ in varus, progressing until the neutral alignment around 18 months. After this, the knees gradually pass into the valgus form, which becomes more pronounced at age 3, progressively decreasing gradually to 6-7 years, thus remaining constant until the end of growth. Devem fazer parte da avaliação clínica a medida da distância intercondilar (DIC) para o geno varo e distância intermaleolar (DIM) para o geno valgo. Most children who are presented with knee valgus are carriers of physiological valgus gene. When the valgus genus persists in pre-adolescence the possibility of spontaneous correction is remote. For the patient, walking can become complicated, because of the knees that come into friction or collide with each other. Tribastone F [3] cites a relationship between valgus knees and flat feet.

In relation to the increase in DIM, the foot tends to support the floor on its medial edge, where it finds greater support and the plant flattens. Verderi E [4] considers that in genu valgum, in more structured cases, imbalance of the plantar arch may occur, causing flattened flat feet.

Farias JP [5] Flat feet can be defined as feet with strongly low or absent arches when submitted to loading. When there is a valgus

Correspondence to: Fernando Cal Garcia Filho; Residency Preceptor in the Orthopedic Department of the Martagão Gesteira Children's Hospital. Apt. 101, Graça. 40150-122, Salvador, Brazil. Tel: +55 71 99971-2222. E-mail: garciafilho59@gmail.com

Key words: Genu Valgum, Flat Feet, Medial Longitudinal Arch, IMD

Received: September 26, 2017; Accepted: October 23, 2017; Published: October 24, 2017 
angulation of the calcaneus are called flat feet valgus or pronated feet.

In most cases, the flat feet of children are flexible, that is, with these apparent arches when they do not support weight, they are frequently present in varying degrees in the children at the beginning of the march, being common the familiar occurrence of characteristics of articular hypermobility, are asymptomatic and perfectly functional and tend to involute with growth, that is, to develop plantar arches and to rectify the calcaneal valgus spontaneously. Although these characteristics of benignity represent the condition that is most frequently seen in pediatric orthopedic clinics, along with axis changes (valgus and varus). Every child can present varying degrees of flat feet at the beginning of the gait. The formation of the resting plantar arch depends on the shape and arrangement of the bones and the tension of the ligaments. At this age the ligament elasticity is pronounced and tends to remain until the age of three. This joint hypermobility, which is still influenced by familial factors, associated with a greater amount of cartilaginous tissue of the skeleton, will justify the planning of the internal arch in the orthostatic position. With growth, especially after 3 years, there is a reduction in elasticity, hence joint hypermobility, and also a progressive maturation of the skeleton, justifying the progressive tendency of the change in the valgus shape of the infant foot to the traditional foot shape adult. Morley AJH [6] published the results of the clinical incidence of flat feet in several age groups of children, concluding that at 18 months, $97 \%$ of the children had flat feet and only $4 \%$ of the 11 to 12 years old in patients without a history of treatment orthopedic. Staheli LT [7], in a similar study, showed that the mean of 2 years old children had flat feet and that the tendency to develop plantar arches was around 5 - 6 years old.

Angular deformities of the lower limbs are known to be one of the major complaints in children and most often associated with deformities of the feet (flat feet). There is still no study in the specific literature regarding the correlation of both, although this association is frequently seen in practice.

Thus, the present study evaluated the results obtained from the correlation of these deformities in the child.

\section{Objective}

To demonstrate the association between Genu Valgum and Flat Feet in children treated at the Orthopedics Clinic of the Martagão Gesteira Children's Hospital, based on gender, age and weight ranges.

\section{Methods}

This is a descriptive study, with a duration of 05 months, in children of both sexes, aged between 2 and 14 years, with intermalleolar distance equal to or greater than $6 \mathrm{~cm}$, patients of spontaneous demand from Martagão Gesteira Children`s Hospital - HIMG. The selection criteria of the study population was the Intermalleolar Distance (IMD) greater than 6 centimeters, which characterizes the diagnosis for Genu Valgum.

Patients who had associated baseline pathologies and / or those who did not sign the informed consent form were used as exclusion criteria for the study population.

Continuous variables were age, intermalleolar distance, and the qualitative variable was sex. All procedures were performed in Martagão Gesteira Children`s Hospital, from January 2013 to May 2013.

A total of 44 patients were treated from January to May 2013. Prior to the collection of any data, the objective of the study was explained to the responsible of each child, exempting him from any obligation to participate in the research and ensuring the patient's privacy. After the authorization and signing of the free and informed consent, data collection was started. Patient identification was made with the patient's age, date of birth, sex, telephone, place of residence, name of the person in charge and degree of relationship. Foot evaluation was performed by the Jack Test (Passive Hyperextension of the Hallux), Foot Tip Test, IMD measurement and prevalent side of angular alteration and foot deformity - bilateral, left or right.

Statistical Package for the Social Sciences SPSS (SPSS Inc., Chicago, Illinois, USA, Release 17.0) was used for the construction of the database and statistical calculations. Data analysis was performed using descriptive statistics. The results of the quantitative variables were presented as mean standard deviation or median and interquartile range according to the distribution of the variable. Categorical variables were expressed as absolute and relative frequency.

The Student's t-test was used, as well as the Kruskal-Wallis test for the independent variables, and the confidence interval (CI) was 95\% (p $<0.05$ ). For an adequate scientific basis of the analysis and discussion of the results found, updated literature on the subject was used, coming from the scientific references.

\section{Results}

Of the 44 patients studied, $13(29.50 \%)$ were female and 31 (70.50\%) were male. There was agreement on the number of patients from the inner cities and patients from the capital with a frequency of $22(50.00 \%)$ patients for each group studied. The mean age of the population was $3.00 \pm 1.80$, with a mode of 2.00 years, $34(77.30 \%)$ patients presented age equal to or less than 3 years and only $10(22.70 \%)$ presented higher ages. Table 1.

It was verified that, in relation to the quartiles for the age, the quartile 25 ( 2 years) coincided with the median, so $50 \%$ of the patients were younger than or equal to 2 years. Three patients had atypical ages (outliers), aged 5 years, 8 years and 12 years, according to Chart 1 . Table 2 .

Another data evaluated was the intermalleolar distance (IMD), which had a minimum value of $6.50 \mathrm{~cm}$ and a maximum of $16.00 \mathrm{~cm}$, the mean was $9.18 \pm 2.00 \mathrm{~cm}$. The range of 6.0 to $8.9 \mathrm{~cm}$ was the most frequent among 20 patients, representing $45.5 \%$ of the total, $100 \%$ of which were bilateral alterations. These data are presented in Table 3.

When related to IMD with the genders, male and female, through Student's $t$ test, there was no significance among them $(p=0.70)$, as shown in Table 4.

In order to correlate IMD with the age ranges by means of the Student's t test, no significance association was found between both ( $\mathrm{p}$ $=0.74)$, the result is presented in Table 5 .

Checking the association between the weight bands and the IMD, through the independent samples test of Kruskal-Wallis, no statistical significance was verified $(\mathrm{p}=0.40)$. Chart 2 shows the weight bands and their respective quartiles.

Regarding the evaluation of the feet, 44 (100\%) patients presented flexible flat feet, all with bilateral alterations

\section{Discussion}

Angular changes of the knee are very common in pediatric orthopedics. Associated with this pathology, flat feet appear frequently, but we do not see this association frequently in the literature, so this 
between knee extension and supination of the hindfoot. Tiberio D [9] and Hamill J [10]. Thus, Powers et al [11] and Labotz [12] suggest that a "pathophysiological cascade" occurs where excessive pronation or supination of the foot may lead to an increase in the medial or lateral rotation of the tibia in relation to the femur and, consequently, to the increase or decreased physiological valgus of the knee.

On the other hand, in a descending system, Cailliet [13] suggests that if there is an increase in knee valgus, the foot will protrude, as the

Table 1. Demografic Data.

\begin{tabular}{|c|c|c|}
\hline Data & Results & (\%) \\
\hline Gender & & 29,50 \\
\hline Female & 13 & 70,50 \\
\hline Male & 31 & \\
\hline Provenance & & 50,00 \\
\hline Capital & 22 & 50,00 \\
\hline Inner Cities & & \\
\hline Age & 34 & 77,30 \\
\hline$\leq 3$ years & 10 & 22,70 \\
\hline 3years & $3,00 \pm 1,80$ & \\
\hline Mean SD & 02 years & $(\%)$ \\
\hline Mode & Results & \\
\hline Data & & 29,50 \\
\hline Gender & 31 & 70,50 \\
\hline Female & & \\
\hline Male & & \\
\hline
\end{tabular}

Table 2. Patient Weight and Height

\begin{tabular}{|c|c|}
\hline Data & Results \\
\hline Weight $(\mathrm{Kg})$ & $17,71 \pm 6,22$ \\
\hline Mean \pm SD & 12,10 \\
\hline Minimum & 50,00 \\
\hline Maximum & \\
\hline Height $(\mathrm{cm})$ & $98,64 \pm 11,66$ \\
\hline Mean \pm SD & 84,00 \\
\hline Minimum & 153,00 \\
\hline Maximum & \\
\hline
\end{tabular}

Table 3. Intermalleolar Distance Distribution (cm).

\begin{tabular}{|c|c|}
\hline Data & Results \\
\hline$\underline{\text { IMD }(\mathrm{cm})}$ & \\
\hline Mean \pm SD & $9,18 \pm 2,00$ \\
\hline Minimum & 6,50 \\
\hline Maximum & 16,00 \\
\hline IMD Ranges $(\mathrm{cm})$ & $20(45,50 \%)$ \\
\hline $6-8,9$ & $19(43,20 \%)$ \\
\hline $9-11,9$ & $4(9,10 \%)$ \\
\hline $12-14,9$ & $1(2,30 \%)$ \\
\hline $15-17,9$ & $44(100 \%)$ \\
\hline Total & \\
\hline &
\end{tabular}

Table 4. Student's $t$ test for IMD and gender variables.

\begin{tabular}{|c|c|c|c|c|c|}
\hline & Gender & Mean \pm SD & p & $\begin{array}{c}\text { CI (95\%) } \\
\text { Minimum }\end{array}$ & Maximum \\
\hline IMD & Female & $9,00 \pm 2,16$ & 0,70 & $-1,60$ & 1,09 \\
\hline & Male & $9,25 \pm 1,96$ & & & \\
\hline
\end{tabular}

Table 5. Student's $t$ test for IMD and gender variables.

\begin{tabular}{|c|c|c|c|c|c|}
\hline & Age Range & Mean \pm SD & p & $\begin{array}{c}\text { CI (95\%) } \\
\text { Minimum }\end{array}$ & Maximum \\
\hline IMD & $\leq 3$ & $9,23 \pm 2,14$ & 0,74 & $-1,23$ & 1,70 \\
\hline & $>3$ & $9,00 \pm 1,50$ & & & \\
\hline
\end{tabular}

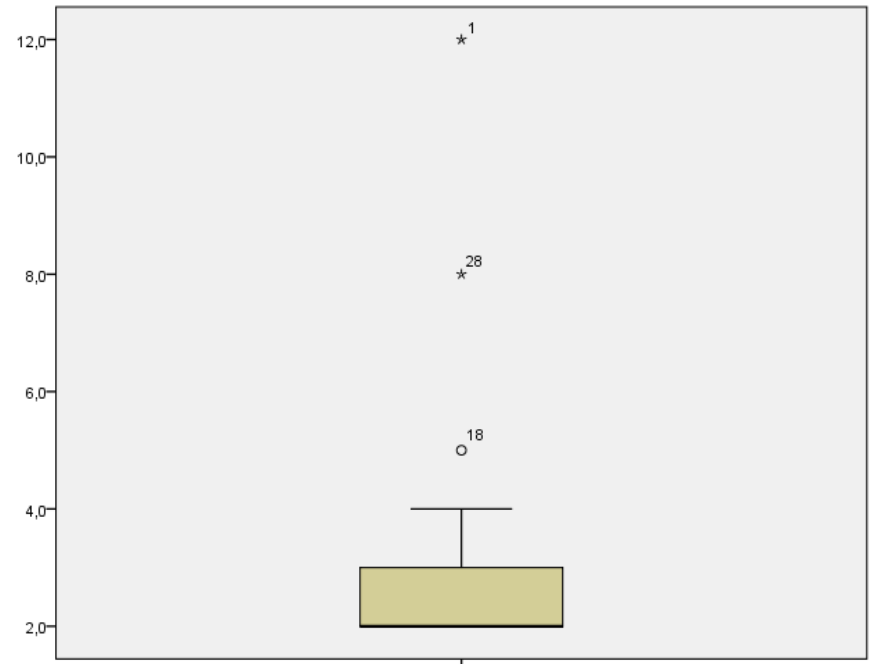

AGE

Chart 1. Distribution chart of quartiles for age.

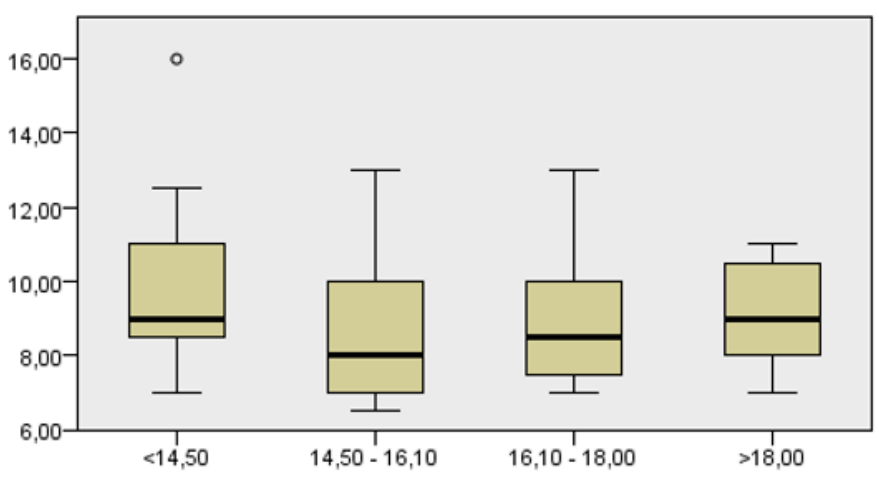

IMD

WEIGHT RANGE

Chart 2. Distribution chart of quartiles for age.

research attempts to contribute to a better evaluation of the association of these two clinical entities.

The present study reports the casuistry of patients who presented an intermolar distance of more than 6 centimeters, which is diagnostic for valgus, and patients with flexible flat feet. The initial proposal of this study provided for the evaluation of 100 children attended at the orthopedic clinic of the Children's Hospital Martagão Gesteira between January and May 2013, but at the end of the 05 months of the study 44 patients were studied, the reduced " $n$ " to be explained by a large number of patients coming from inner cities 22 (50\%), this implies in patients' return difficulties to follow-up, thus many patients who are in treatment who should return every 03 months for a new evaluation end up not attending the consultations or even drop out due to lack of financial means to pay for transportation costs.

This study should be used as a starting point for others with this same theme. There is little research that directly compares valgus with flat feet. According to Williams et al. Williams DS [8], a greater or lesser movement of the subtalar joint is usually associated with an enlarged or lowered plantar arch, which can cause knee injuries due to the mutual mechanical influence between these two joints, through the rotational component of the tibia. Excessive or prolonged pronation may delay lateral rotation of the tibia and alter the desirable rhythm 
weight bearing plumb line will fall into the normal median line and may overload the arch longitudinal medial. Verderi [14] also proposes that valgus genus, in certain cases, can result in an imbalance of the plantar arch, causing pronated and flat feet.

This study verified $100 \%$ of patients with valgus and flat feet. This correlation was also seen by Silva et al [15] in a similar study, which showed a correlation between valgus and flat feet.

The development of the foot involves the formation of plantar arches. Among them is the medial longitudinal arch (MLA) and changes in its shape alter the functionality of the foot leading to complications of all posture. Saltzman [16]. Healthy children have a physiologically flat foot, developing their arches with growth and development. Some studies describe ages at which maturation of MLA may occur. Magee [17] considers that from the age of 2 the shape of the child's foot is similar to that of the adult. Volpon [18] considers the phase of major alteration of MLA between 2 and 6 years. Age is the main predictive factor for flat feet, and the prevalence of flat feet decreases progressively with age. Pfeiffer [19].

In this study, 34 patients had ages equal to or less than 03 years, which corresponds to $77,30 \%$ of all patients, and only 10 were older, these data are in agreement with the literature, Echarri et al [20] reported a significant increase in the number of patients in the study, with a mean age of 3 years or less, which corresponds to $77,30 \%$ of all patients, and only 10 were older. prevalence of flat feet of $70 \%$ in children aged 3 to 4 years; Lin et al. [21] found that the prevalence of flat feet decreased from $57 \%$ in children 2 to 3 years of age to $21 \%$ in children 5 to 6 years of age.

Pfeiffer [19] reports that boys had a significantly greater tendency to flat feet than girls, the prevalence of flat feet in boys was $52 \%$ and in girls it was $36 \%$. In our study of the 44 patients studied 13 (29.50\%) were female and 31 (70.50\%) were male.

Our study revealed that the mean age of the population was 3.00 +1.80 years, according to the literature, which points to a higher incidence of Genu Valgum in children aged 2 to 5 years according to Volpon [22]. and reaching the maximum around 4 years. Volpon [22]. The trend towards valgus in this age group is observed in the chart below, by Campagnolo et al [23] which indicates the physiological tendency of Genu Varum up to 2 years, then trend to Genu Valgum between 2 and 5 years and from that age, a trend towards stabilization.

The anthropometric data evaluated were weight and height. The mean weight was $17.70 \pm 6.20 \mathrm{~kg}$. The mean height was $98.60 \pm 11.60 \mathrm{~cm}$.

Another data evaluated was the intermaleolar distance (IMD), which had a minimum value of $6.50 \mathrm{~cm}$ and a maximum of 16.00 $\mathrm{cm}$, the mean was $9.18 \pm 2.00 \mathrm{~cm}$, the normal value is less than $2 \mathrm{~cm}$. Campagnolo et al. [23] classifies genu valgum according to IMD, mild cases comprise the range of $2 \mathrm{~cm}$ to $5 \mathrm{~cm}$, these cases are usually physiological, they may drag up to 08 years, do not need treatment and they tend to correct spontaneously, which is why we chose to select patients who presented IMD greater than $06 \mathrm{~cm}$; moderate, IMD between $5 \mathrm{~cm}$ and $9 \mathrm{~cm}$; and severe, when IMD greater than 09 $\mathrm{cm}$, these cases are more associated with pathological genu valgum and require treatment, which may be conservative, which includes replacement of vitamin complex, use of orthotics and physiotherapy; or surgery, which is reserved for the most serious cases and does not respond to conservative treatment. Our study population had 20 patients, representing $45.50 \%$, with IMD between 6.0 and $8.9 \mathrm{~cm}$, that is, patients classified as moderate. All patients received conservative treatment, and should be reassessed every 03 months, to attest the evolution of the treatment and to evaluate the necessity or not of the surgical treatment. In most cases, conservatively treated patients evolve well and have regression of IMD, few cases require surgical intervention.

Regarding the treatment of flat feet, the subject is controversial and presents divergences in the literature, Viladot [24] recommends treatment from 02 or 03 years of age. Rose [25] states that treatment should never be performed after 6 years. García-Rodriguez et al. [26] reports that traditionally, flat feet have been treated with orthopedic insoles or boots. Our work is in agreement with the literature, because all our patients receive the treatment, which is concomitant with genu valgum, because if there is an association between the pathologies, it is expected that the correction of one pathology will force the correction of the other and vice versa.

When related to IMD with the genders, male and female, through Student's t test, there was no significant difference between them $(p=0.70)$

In order to correlate IMD with the age ranges by Student's t test, no association of significance was found between both $(p=0.74)$.

There are some hypotheses suggesting that individuals with overweight and obesity would be more likely to postural deviations among them than valgum. However, verifying the association between the weight bands and the IMD, through the Kruskal-Wallis independent test statistically significant $(\mathrm{p}=0.40)$. This data is confirmed by Garcia et al, who in a recent study did not demonstrate a direct correlation between obesity and valgus. Recent studies suggest a new association between obesity and flat feet, Souza et al describes in their study that obese children, due to excess body mass, may present changes in foot morphology, with an even greater reduction in MLA [27,28].

Obesity is the 21 st century epidemic and at the same time, Genu Valgum and flat feet are very common orthopedic pathologies. Thus, indications of correlation between pathologies by different aspects related to the theme, such as weight, can serve as a stimulus for the development of new research, seeking associations between valgus, flat feet and obesity. Thus, this research will serve as a basis for future studies with a larger number of patients, in order to provide a comprehensive assessment of the universe of Brazilian children.

\section{Conclusion}

The present study demonstrated that there is an association between genu valgum and flat feet in their totality, with a male predominance of 2: 1, mean age of 03 years, and weight ranging from $12 \mathrm{~kg}$ to $50 \mathrm{~kg}$.

\section{Authorship and contribution}

Fernando Cal Garcia Filho: substantial contributions to conception and design of the present study. Revised the study critically for important intellectual content. Made a final approval of the version to be published and agreed to act as guarantor of the work.

Breno Leite Luz: substantial contributions to analysis and interpretation of data. Contributed to the drafting of the article. Made a final approval of the version to be published and agreed to act as guarantor of the work.

Mateus de Oliveira Trindade: substantial contributions to conception and design of the present study. Revised the study critically for important intellectual content. Made a final approval of the version to be published and agreed to act as guarantor of the work. 
Lucas Cortizo Garcia: substantial contributions to acquisition of data and drafting the article. Made a final approval of the version to be published and agreed to act as guarantor of the work.

Magda Leão Pinheiro: substantial contributions to analysis and interpretation of data. Contributed to the drafting of the article. Made a final approval of the version to be published and agreed to act as guarantor of the work.

Fernanda Cortizo Garcia: substantial contributions to analysis and interpretation of data. Contributed to the drafting of the article. Made a final approval of the version to be published and agreed to act as guarantor of the work.

Matheus Vasconcelos Goes Mendes: substantial contributions to analysis and interpretation of data. Contributed to the drafting of the article. Made a final approval of the version to be published and agreed to act as guarantor of the work.

\section{Funding information and competing interests}

The present study has not been funded by any instutition and all its costs were covered by the authors.

The Authors disclose that the present study has no financial or non-financial conflicts of interests.

\section{References}

1. Volpon JB (2011) Texto básico de ortopedia e traumatologia para o acadêmico - apostila de graduação. Ed. 1. São Paulo. FMRP. Doenças congênitas do desenvolvimento 93-110.

2. Bertol P (2003) Ortopedia pediátrica. Rio de Janeiro Revinter 202-205.

3. Tribastone $\mathrm{F}$ (2001) Tratado de exercícios corretivos aplicados à reeducação motora postural. Barueri: Manole

4. Verderi E (2001) Programa de educação postural. São Paulo: Phort.

5. Farias JP, Galvão S (2003) Ortoprdia Pediátrica. Rio de Janeiro: Revinter 223-232.

6. Morley AJH (1957) Knock-knee in children. Br Med J 12: 976-979.

7. Staheli LT, Giffin L (1980) Corrective shoes for children: a survey of current practice. Pediatrics 65: 13-17. [Crossref]

8. Williams DS 3rd, McClay IS, Hamill J (2001) Arch structure and injury patterns in runners. Clin Biomech (Bristol, Avon) 16: 341-347. [Crossref]

9. Tiberio D (1988) The effect of excessive subtalar joint pronation on patellofemoral mechanics: a theoretical model. J Orthop Sports Phys Ther 9: 160-165.
10. Hamill J, Bates BT, Holt KG (1992) Timing of lower extremity joint actions during treadmill running. Med Sci Sports Exerc 24: 807-813. [Crossref]

11. Powers CM, Maffucci R, Hampton S (1995) Rearfoot posture in subjects with patellofemoral pain. J Orthop Sports Phys Ther 22: 155-160. [Crossref]

12. Labotz M (2004) Patellofemoral syndrome: diagnostic pointers and individualized treatment. Phys Sportsmed 32: 22-29. [Crossref]

13. Cailliet R (1987) Síndromes dolorosas: joelho, dor e incapacidade. São Paulo: Manole

14. Verderi E (2001) Programa de educação postural. São Paulo: Phort.

15. Silva AS, Souza MSC, Morais ER, Silva JMF, Canuto OS, et al. (2005) Prevalência de alterações posturais para prescrição do programa de exercícios em academias de ginástica - PB. Rev Saude Com 1: 124-133.

16. Saltzman CL, Nawoczenski DA, Talbot KD (1995) Measurement of the medial longitudinal arch. Arch Phys Med Rehabil 76: 45-49. [Crossref]

17. Magee DJ (2002) Avaliação Musculoesuelética. Ed. Manole, São Paulo.

18. Volpon JB (1994) Footprint analysis during the growth period. J Pediatr Orthop 14: 83-85. [Crossref]

19. Pfeiffer M, Kotz R, Ledl T, Hauser G, Sluga M (2006) Prevalence of flat foot in preschool-aged children. Pediatrics 118: 634-639. [Crossref]

20. Echarri JJ, Forriol F (2003) The development in footprint morphology in 1851 Congolese children from urban and rural areas, and the relationship between this and wearing shoes. J Pediatr Orthop B 12: 141-146. [Crossref]

21. Lin CJ, Lai KA, Kuan TS, Chou YL (2001) Correlating factors and clinical significance of flexible flatfoot in preschool children. J Pediatr Orthop 21: 378-382. [Crossref]

22. Volpon JB (1995) Modificações fisiológicas e patológicas do joelho durante o crescimento. Rev Bras Ortop 30: 53-56.

23. Campagnolo JL, Neves C (2009) Desvios Axiais dos Membros Inferiores. Rev Port Clin Geral 25: 464-70.

24. VILADOT PERICE A (1954) [New method of statistical investigation of the feet; photopodography]. Clin Lab (Zaragoza) 57: 114-117. [Crossref]

25. Rose GK (1990) Flat feet in children. Br Med J 301: 1330-1331.

26. García-Rodríguez A, Martín-Jiménez F, Carnero-Varo M, Gómez-Gracia E, GómezAracena J, et al. (1999) Flexible Flat Feet in Children: A Real Problem? Pediatrics 103: 84. [Crossref]

27. Viladot R, Aláez J (1984) Dez Lições de Patologia do Pé. s.l. Roca 55-76.

28. Harfush Nasser LA (2007) Deformidades angulares en los miembros inferiores Medigraphic. Artemisa em línea 3: 90-97.

Copyright: (2017 Filho FCG. This is an open-access article distributed under the terms of the Creative Commons Attribution License, which permits unrestricted use, distribution, and reproduction in any medium, provided the original author and source are credited. 